\title{
Modeling Land-Surface/Atmosphere Dynamics for CHAMMP
}

\author{
Progress Report
}

for Period August 1, 1992 - 31 July, 1993

W. J. Gutowski, Jr.

Iowa State University

Ames, Iowa 50011

January 1993

Prepared for

THE U.S. DEPARTMENT OF ENERGY

AGREEMENT NO. DE-FG02-92ER61473

\section{NOTICE}

This report was prepared as an account of work sponsored by the United States Government. Neither the United States nor the Department of Energy, not any of their employees, makes any warranty, express or implied, or assumes responsibility for the accuracy, completeness, of usefulness of any information, apparatus, product or process accuracy, or represents that its use would not infringe privately-owned rights. disclosed or represents that its use would not infinge privaty- 


\begin{abstract}
Project progress is described on grant DE-FG02-92ER61473, a DOE CHAMMP project to model the land-surface/atmosphere coupling in a heterogeneous environment. This work is a collaboration between scientists at Iowa State University and the University of New Hampshire. Work has proceeded in two areas: baseline model coupling and data base development for rodel validation. The core model elements (land model, atmosphere model) have been ported to the Principal Investigator's cumputing system and baseline coupling has commenced. The initial target data base is the set of observations from the FIFE field campaign, which is in the process of being acquired. For the remainder of the project period, additional data from the region surrounding the FIFE site and from other field campaigns will be acquired to determine how to best extrapolate results from the initial target region to the rest of the globe. In addition, variants of the coupled model will be used to perform experiments examining resolution requirements and coupling strategies for land-atmosphere coupling in a heterogeneous environment.
\end{abstract}




\section{INTRODUCTION}

This report describes project progress for the initial period of DOE grant DEFG02-92ER61473 to Iowa State University (ISU). Activities during this period have focused on the research plan's Phase 1, which is guided by the question,

"What is the appropriate level of spatial and temporal resolution for capturing

surface-atmosphere dynamics over a heterogeneous land surface?"

Project efforts for Phase 1 have included activities in two areas: (1) forming the coupled land-atmosphere model that will be used to explore coupling in a heterogeneous environment and (2) developing appropriate data bases to support the modeling effort. Work has proceeded in collaboration with Dr. Charles Vorosmarty and fellow scientists at the University of New Hampshire's (UNH's) Institute for the Study of the Earth, Oceans and Space, a subcontractor to the project.

\section{Project Progress}

\subsection{Coupled Model}

Phase 1 research entails developing a modeling system that couples the AER Local Forecast and Assimilation (ALFA) Model to the UNH surface hydrology and fluvial dynamics model. The ALFA model simulates the atmospheric column of a single grid box, and can be placed over any of the grid boxes spread over the UNH model's simulation domain.

A copy of the ALFA model was obtained from scientists at Atmospheric and Environmental Research (AER), Inc., at the beginning of the grant period. After some effort, the model was successfully ported to the DECstation UNIX environment at ISU. The principal porting difficulty was a FORTRAN compiler bug exposed by the code. Test runs of the ALFA model repeated simulations performed by AER scientists and produced output that matched the AER simulations. Dr. Gutowski has also obtained a copy of the UNH codes, and he has also run them successfully on the ISU system.

The initial coupling of the two models has begun. Coupling occurs primarily through the surface energy fluxes (radiation, sensible heat and latent heat) and precipitation. In our initial effort we are coupling a single UNH model grid to an ALFA model column. 


\subsection{Data Base}

Two meetings involving senior project personnel have been held to determine the data needed and the plan for obtaining it. The first meeting was at UNH near the beginning of the grant period; a second follow-up meeting was held at ISU in December 1992.

This project aims at performing extensive validation of ccupled- model simulations with data observed during field campaigns, so that we are focusing our attention on campaigns that include extensive observations of surface-atmosphere exchange processes. Our initial, exploratory examination of surface-atmosphere coupling will simulate conditions at the site of the First ISLSCP Field Experiment (FIFE; Sellers et al. 1988), which occurred at the Konza Prairie in Kansas. We are in the process of obtaining the requisite FIFE data.

Further data collection planned reflects how we will extend our effort beyond this site. First we will obtain surface and atmospheric boundary conditions that allow us to extend our simulations to neighboring regions in Kansas. This will allow us to asses how well we can extrapolate results from the FIFE site to the broader region. In neighboring regions we will not have the detailed observation set available for FIFE, so our validation of model behavior will be more limited, restricted primarily to comparisons with observed rainfall and river flow.

Second, we will extend our simulations to include other field sites, most notably the site of the Boardman Field Experiment (Doron et al. 1992), a DOE-supported campaign under the Atmospheric Radiation Measurements (ARM) program. Dr. Gutowski has discussed the accessibility of the Boardman data with the project's principal investigator, Dr. Doron.

\subsection{Other}

Before the formal start of the grant, Dr. Gutowski obtained pre-award spending authorization from ISU in order to begin advertising for the grant's postdoctoral research associate position as soon as possible. Advertising was placed in June 1992 and produced several good applicants. After soliciting references from a short list, Dr. Gutowski made an offer that was accepted in October. However, plans were thwarted when the candidate changed his mind at the last moment. Dr. Gutowski has since obtained an agreement with his second choice, Mr. Zekai Ötles, who should arrive at ISU in March 1993 after completing a Ph. D. on analysis of HA.PEX boundary layer data under Prof. John Young at the University of Wisconsin. 
Dr. Gutowski attended a workshop on East-West scientific exchange in late October 1992 in Budapest, Hungary. This meeting had relevance for this project as it has great potential for yielding additional data sets that would be useful for model validation. Consequently, a portion of Dr. Gutowski's travel support came from this grant's funds. A travel report on the workshop was given to the grant monitor, Mr. Michael Riches, in November.

Dr. Gutowski also completed or brought close to completion the publication process on three papers describing DOE-supported research he performed at his previous institution, Atmospheric and Environmental Research, Inc.:

Gutowski, W. J., G. F. McMahon, P. Kirshen and S. Schluchter, 1992: Projecting climate change to small basins: Potential impact of global warming on flooding in South Florida. J. Water Res. Plan. Man. (Accepted pending revision).

Yang, S., and W. J. Gutowski, 1992: On the relationship between tropical Chinese rainfall and the Indian monsoon. J. Meteor. Soc. Japan, 70, 997-1003.

Yang, S., and W. J. Gutowski, 1992: Stationary wave activity in GCM simulations of current and doubled $\mathrm{CO}_{2}$ climates. J. Climate (Submitted).

\section{Plans for the Remainder of the CuRrent Grant Year}

Dr. Gutowski and collaborators will complete the initial coupling of the ALFA and UNH models. They will then complete planned synthetic tests based on the FIFE site to explore how the simulation of land-atmosphere exchange and the local hydrological cycle respond to increasing the horizontal resolution of the surface within one ALFA column. They will also explore what benefits there are, if any, for allowing resolution of the lowest atmospheric layers (that interact directly with the surface) to be higher than for layers above the planetary boundary layer. They will also consider benefits and detriments of various coupling strategies in heterogeneous domains, such as those proposed by Claussen (1991) and Avissar and Chen (1993). as well as considering alternatives suggested by the field data.

Project scientists will complete acquisition of FIFE and related data, will start building a database from Boardman Experiment observations, and will determine (and start to obtain) additional data from other relevant field experiments. 


\section{REFERENCES}

Avissar, R., and F. Chen, 1993: Using the mesoscale kinetic energy (MKE) for the parameterization of mesoscale (subgrid-scale) processes induced by landscape discontinuities in GMC's. Conference on Hydroclimatology, Anaheim, CA., American Meteorological Society, 21-23.

Claussen, M., 1991: Estimation of areally-averaged surface fluxes. Boundary-Layer Metereoroi., 54, 387-410.

Doron, J. C., F. J. Barnes, R. L. Coulter, T. L. Crawford, D. D. Baldocchi, L. Balick, D. R. Cook, D. Cooper, R. J. Dobosy, W. A. Dugas, L. Fritschen, R. L. Hart, L. Hipps, J. M. Hubbe, W. Gao, R. Hicks, R. R. Kirkham, K. E. Kunkel, T. J. Martin, T. P. Meyers, W. Porch, J. D. Shannon, W. J. Shaw, E. Swiatek and C. D. Whiteman, 1992: The Boardman Regional Flux Experiment. Bull. Amer. Meteor. Soc., 73, 1785-1795.

Sellers, P. J., F. G. Hall, G. Asrar, D. E. Strebel and R. E. Murphy, 1988: The First ISLSCP Field Experiment (FIFE). Bull. Amer. Meteor. Soc., 69, 22-27. 

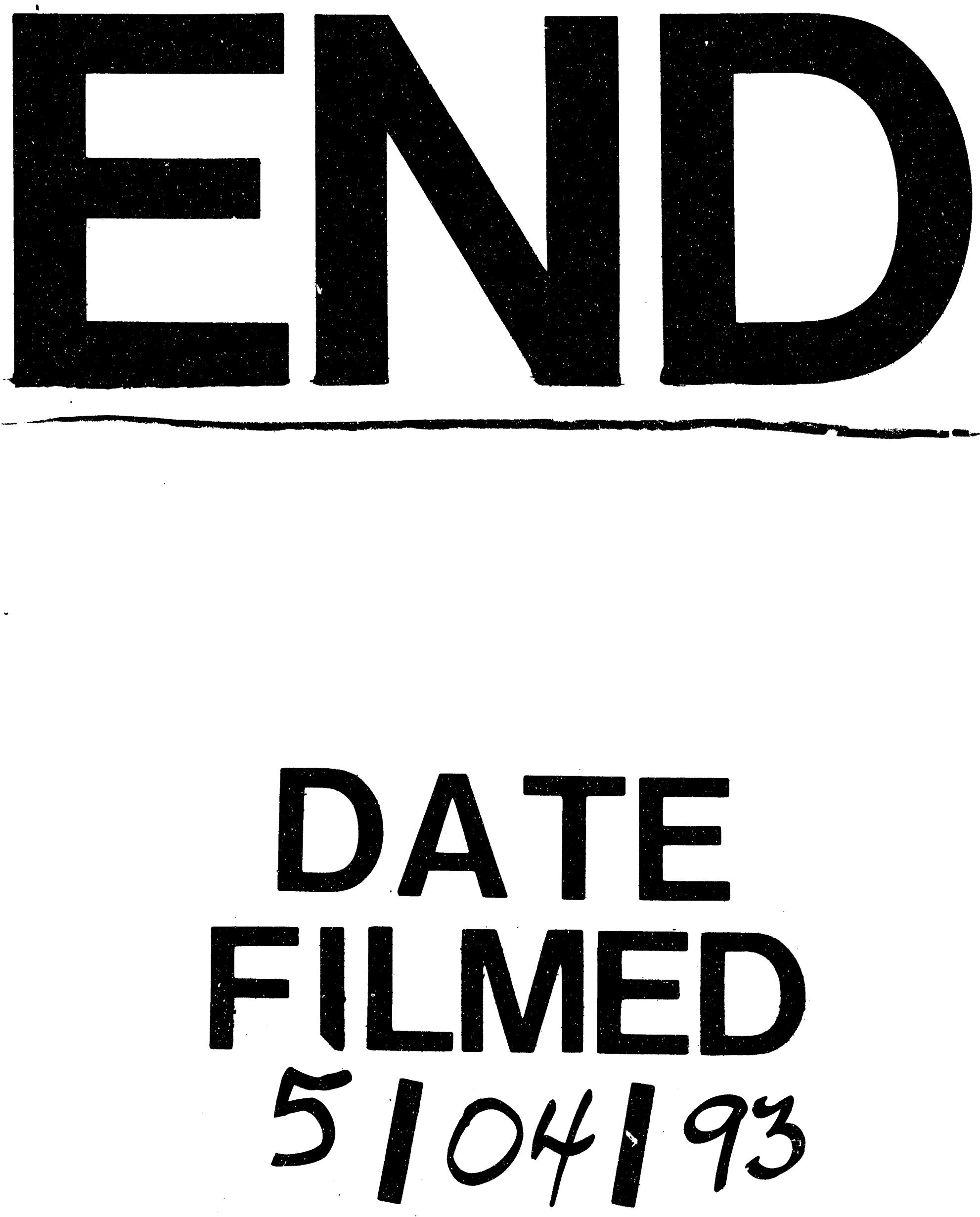
